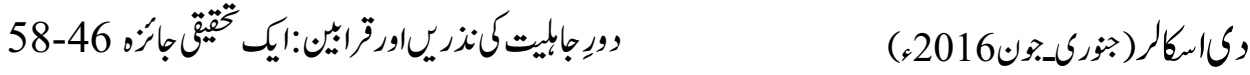

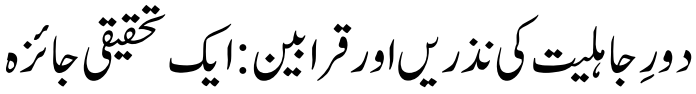

\title{
RITUAL SACRIFICES AND OFFERINGS IN THE NAME OF GOD IN THE PRE-ISLAMIC ERA - A CRITICAL ANALYSIS
}

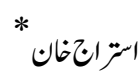

DOI: $10.29370 /$ siarj/issue2ar4

Link: https://doi.org/10.29370/siarj/issue2ar4

\begin{abstract}
:
As presenting gifts and offerings increase love and affiliation between humans, man has also considered it a means of acquiring the pleasure of God and acquiring closeness to Him. Psychologically, those who present gifts seek some sort of benefit from the one who they make the offerings to. Now consider the case of the Creator who has power over everything and He can do whatever He wants. Accordingly, humans seek different ways to acquire His pleasure, show their respect and love. Humans throughout the history have made sacrifices and offerings for God, some in legitimate ways and some illegitimate. Though Allah SWT is free of any need for our presents, gifts, sacrifices and offerings, this is a means that He has provided us to become his beloved. In Islam, the beauty of this system is such that it becomes a means to help the fellow human beings (e.g. in the form of zakat, Sadaqat and Hadaya etc.). In the pre-Islamic times as well, people used to make different forms of offerings which they believed would take them closer to their false gods which were mostly illegitimate and void of any significant benefits to humankind. In this critical inquiry, we have explored those offerings and their underlying motives in detail.
\end{abstract}

KEYWORDS: Offerings,. Hadaya، Ritual Sacrifices, Sadaqat, pre-Islamic era

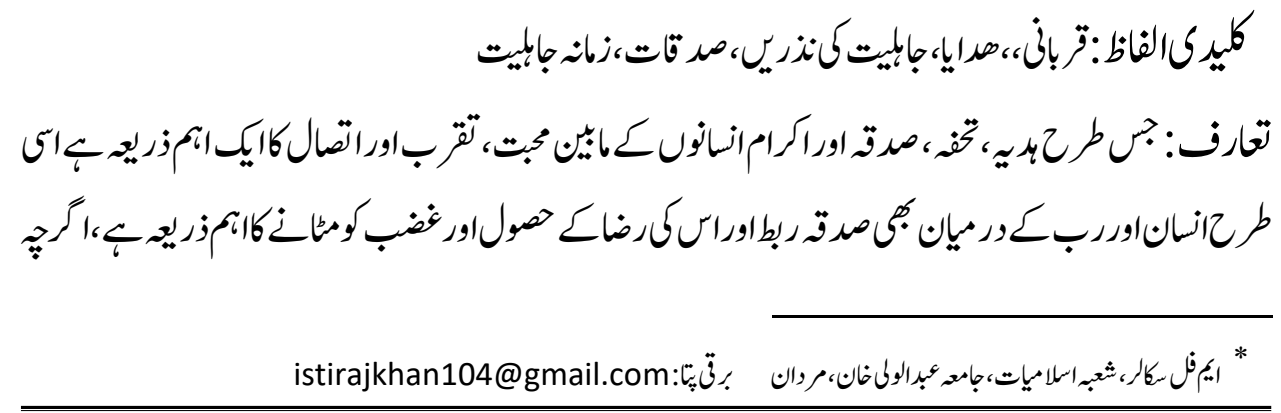




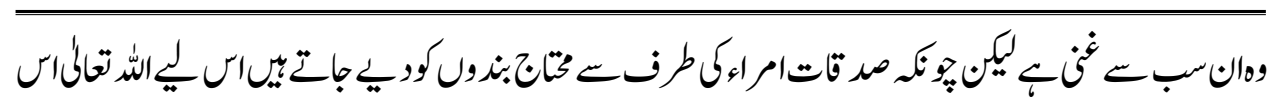
كن

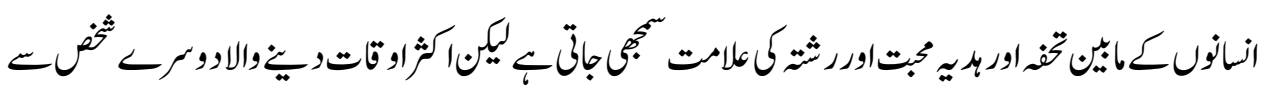

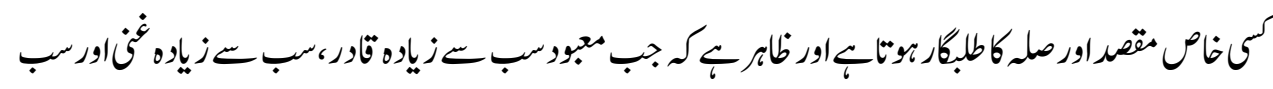

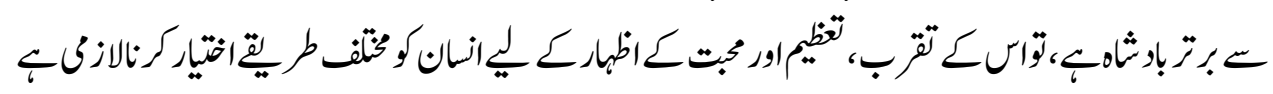

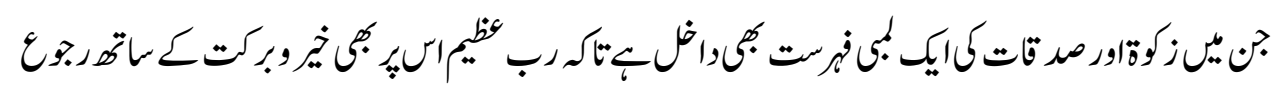

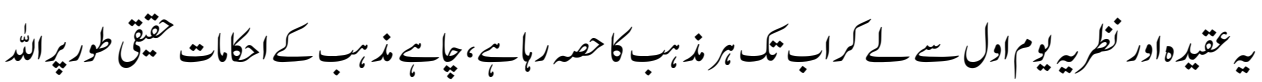

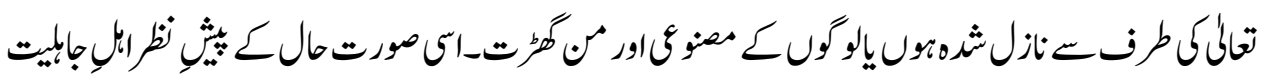

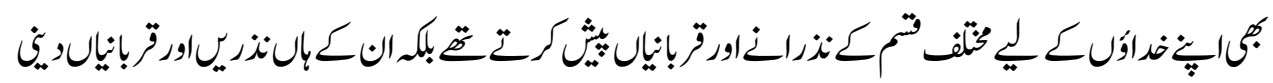

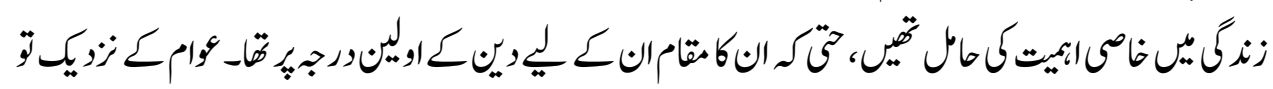

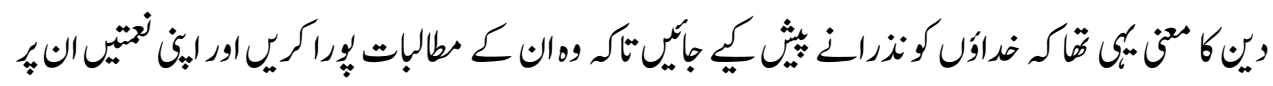

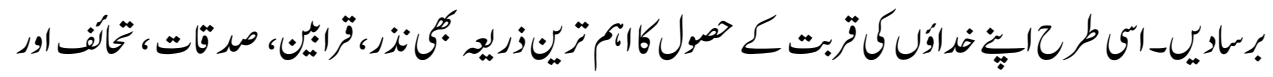

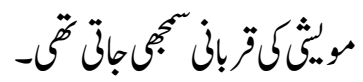

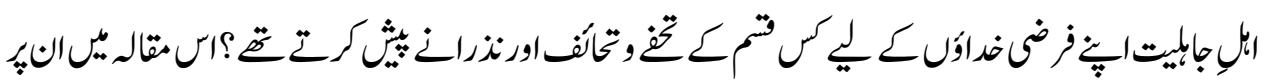

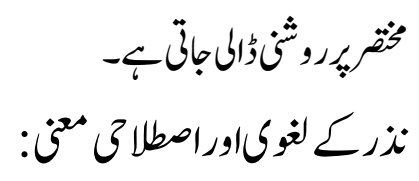

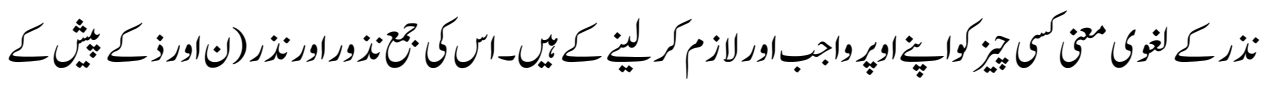

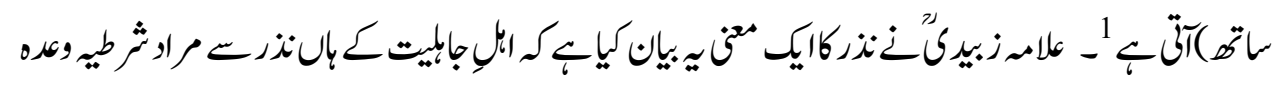

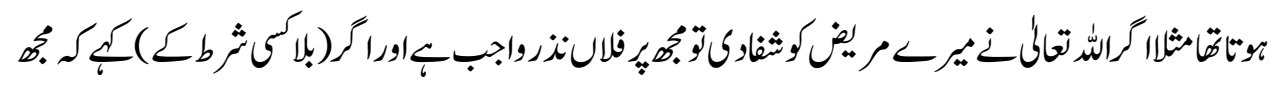

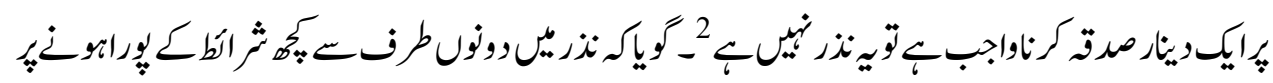

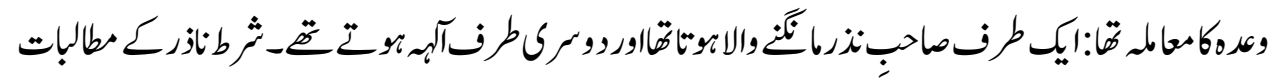

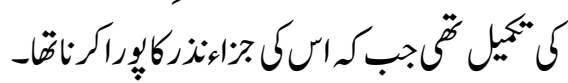

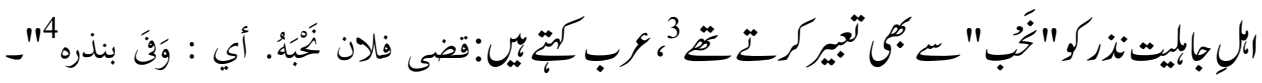




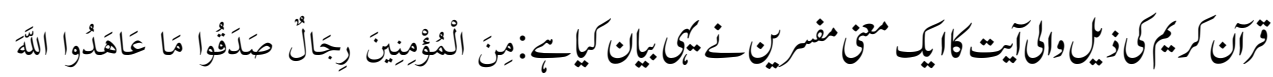

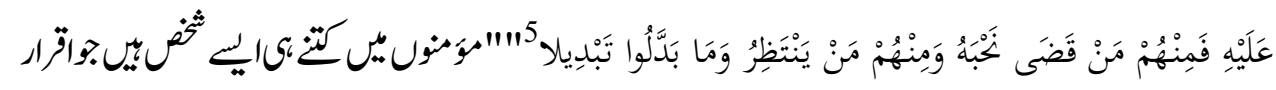

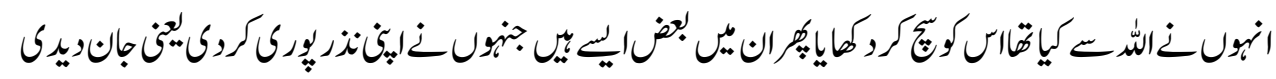

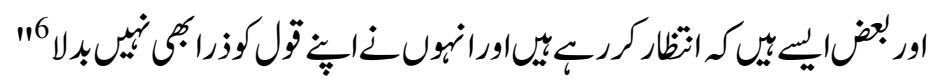

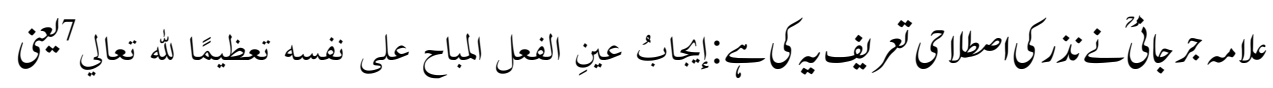

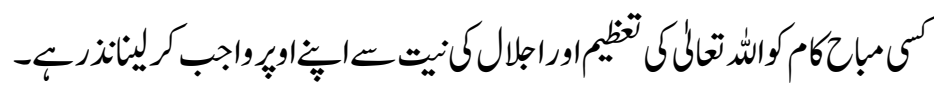

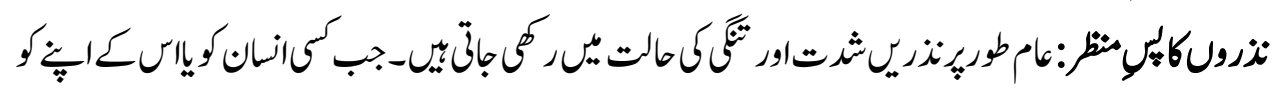

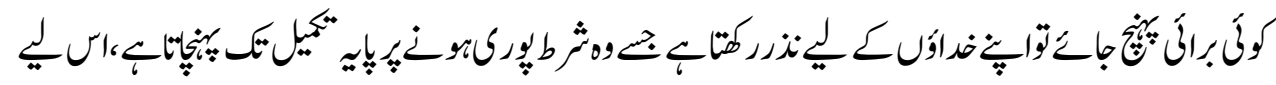

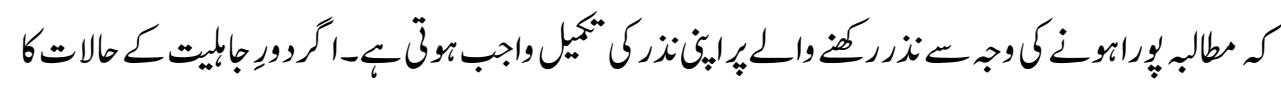

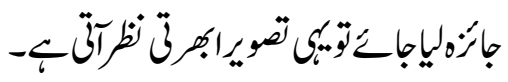

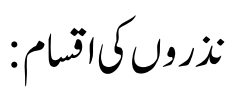

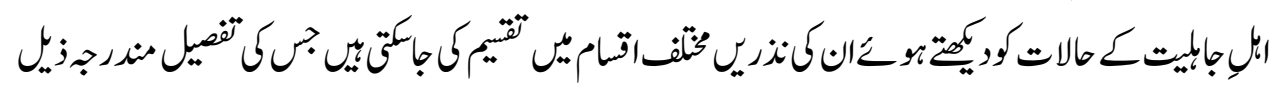
: واجب|ورمندوبنزري:

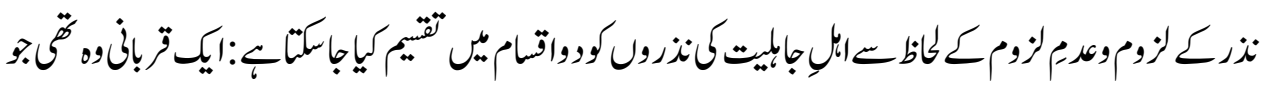

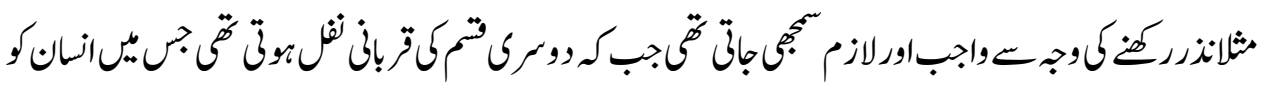

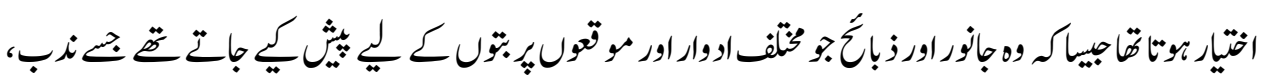

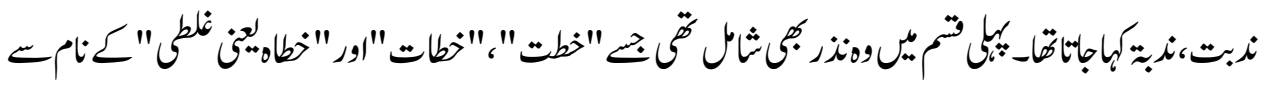

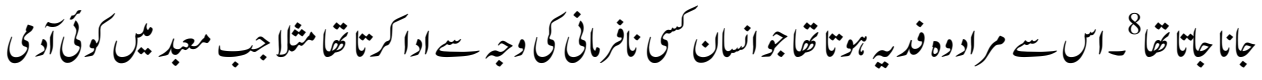

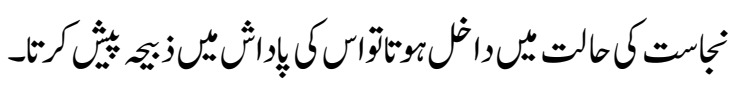

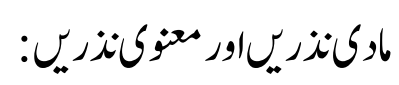

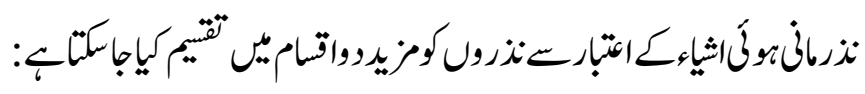

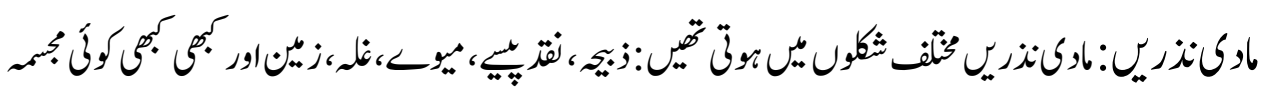




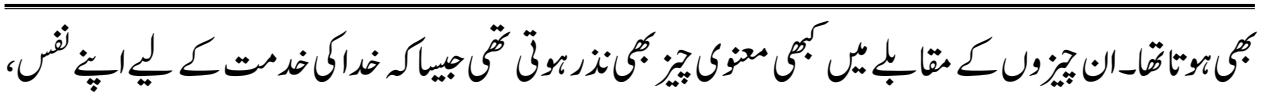

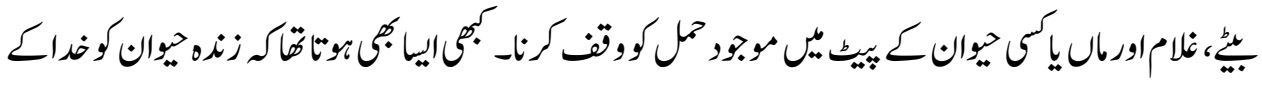

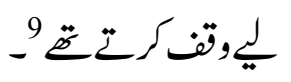

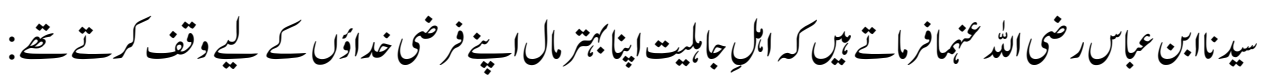

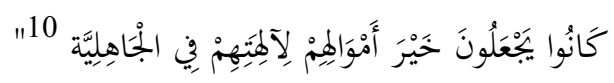

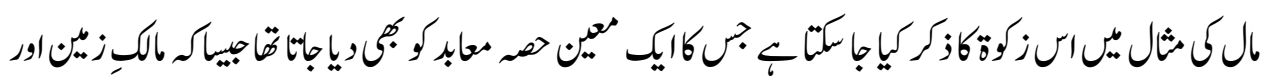

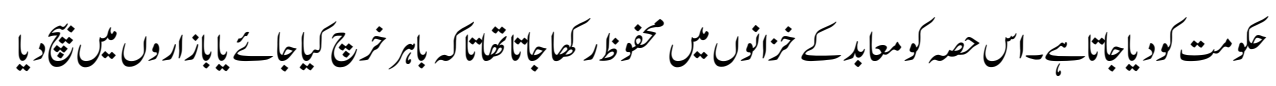

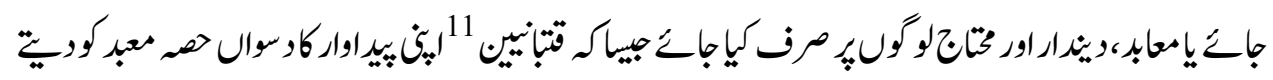

$$
\text { - }
$$

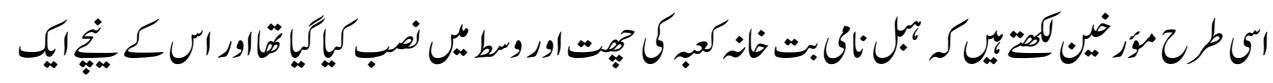

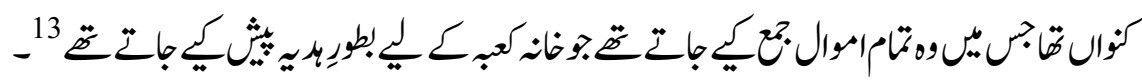

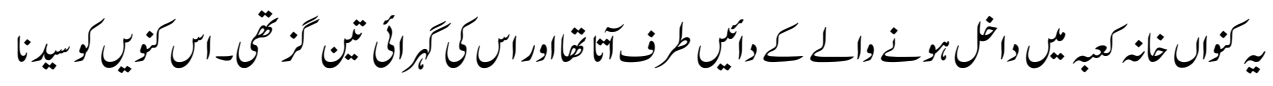

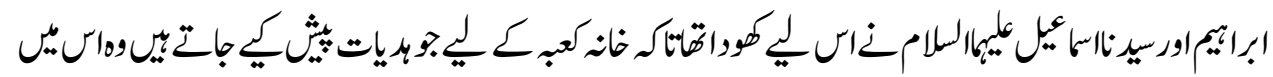

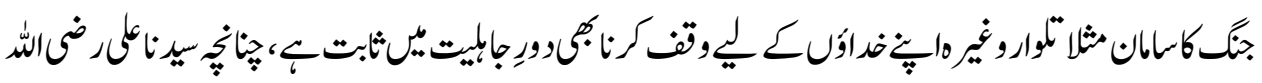

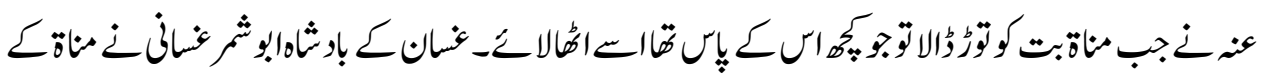

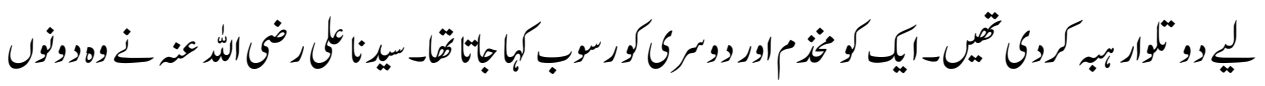

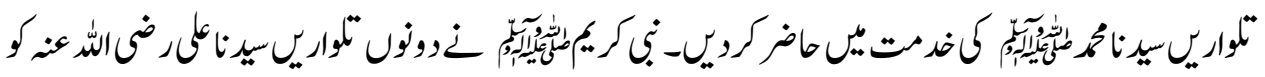

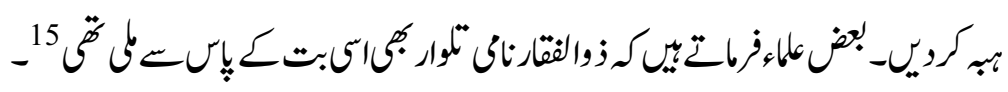

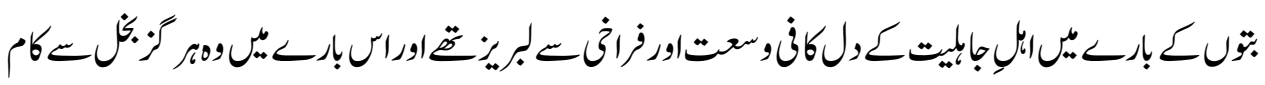

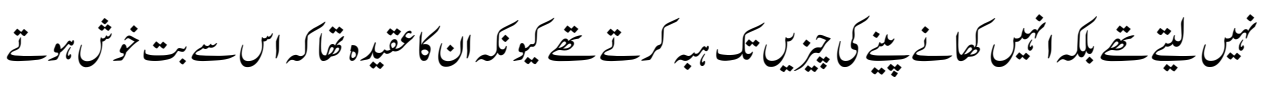

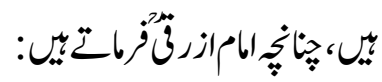
نصب عمرو بن لحي الخلصة بأسفل مكة, فكانوا يلبسوفا القائد ويهدون إليها الشعير والحنطة،

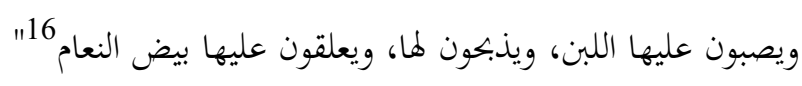




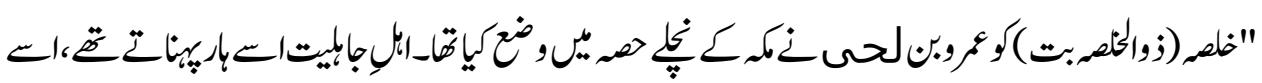

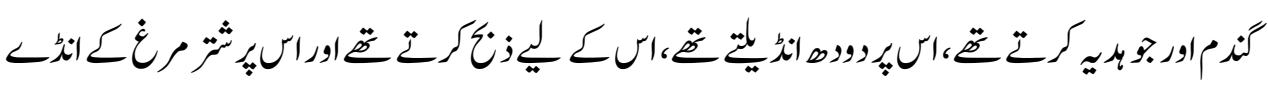

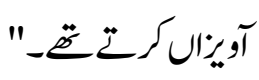

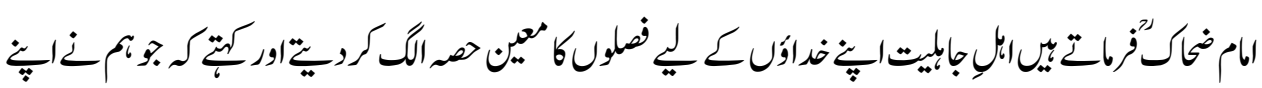

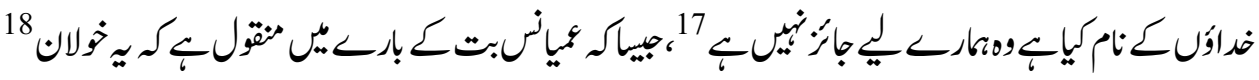

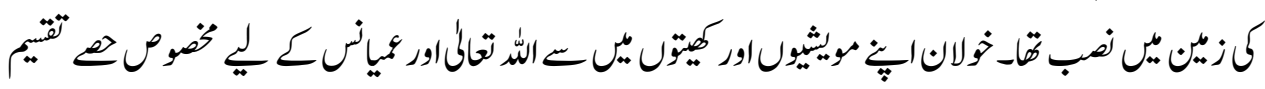

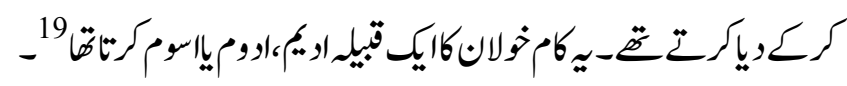

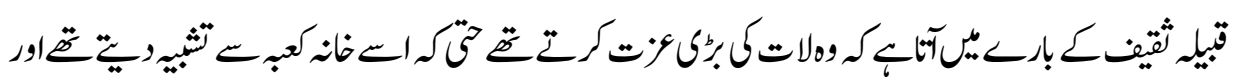

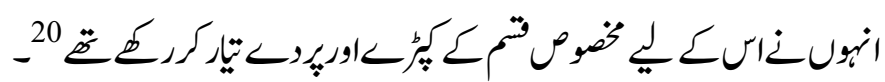

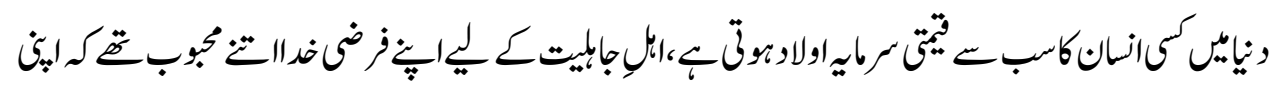

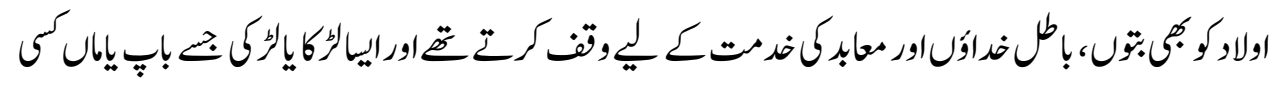

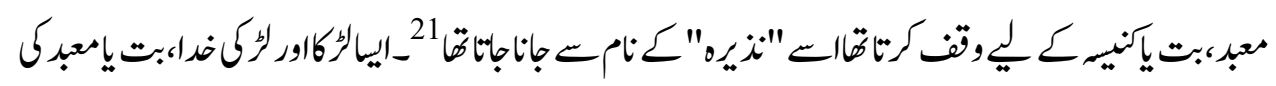

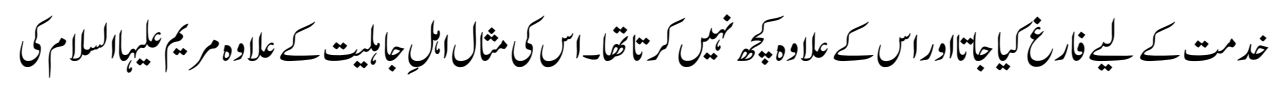

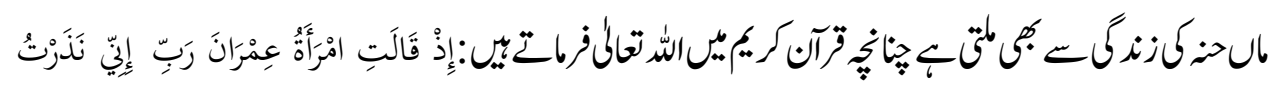

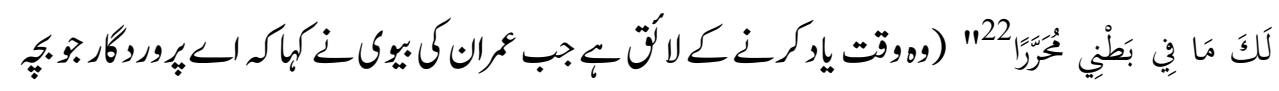

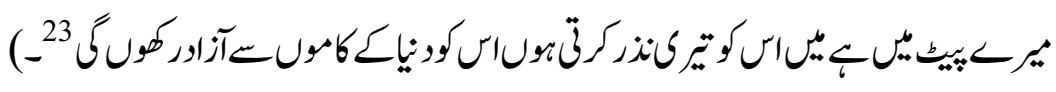

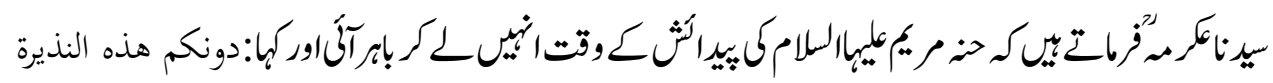

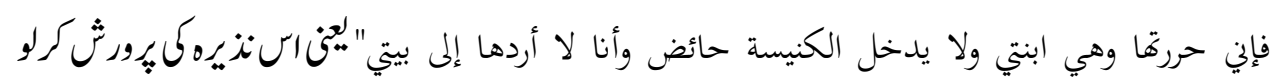

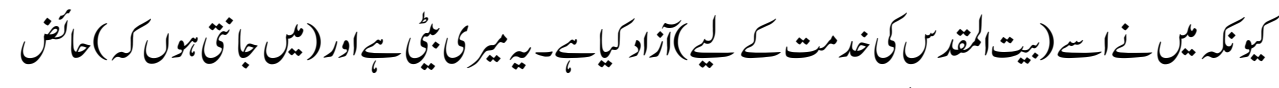

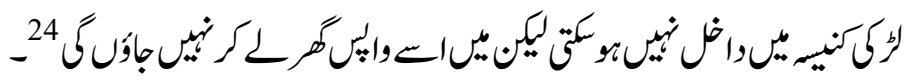

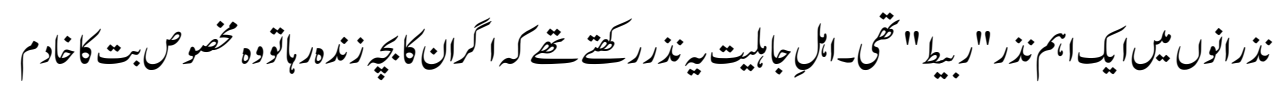

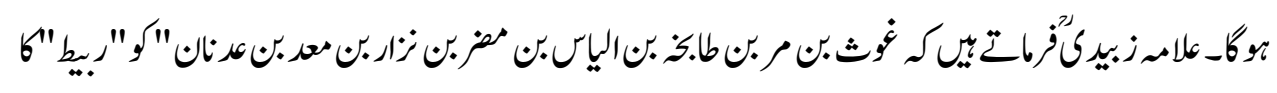

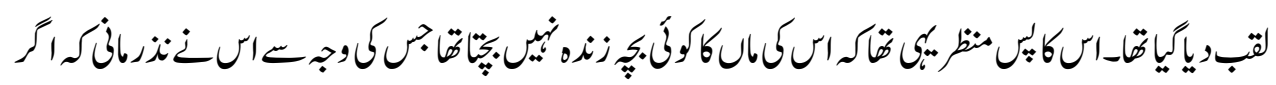

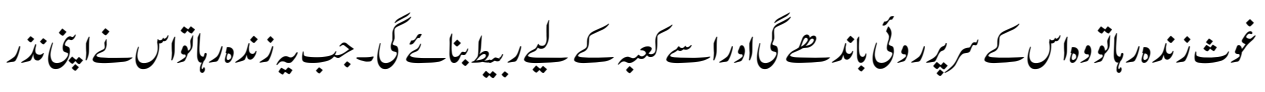




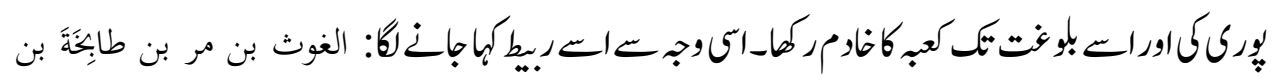

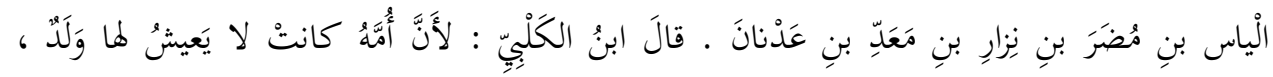

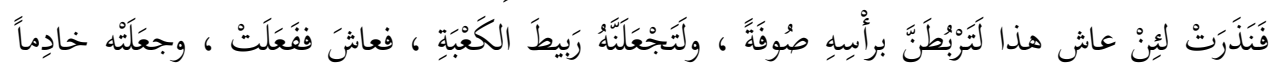

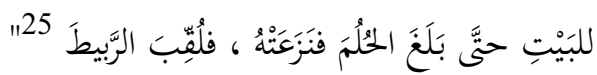

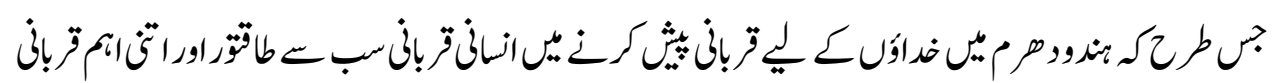

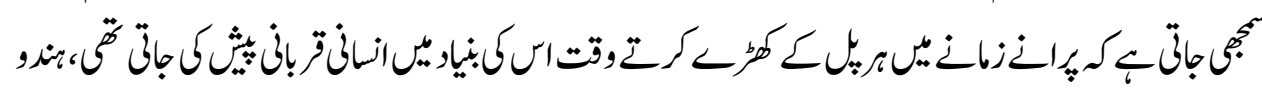

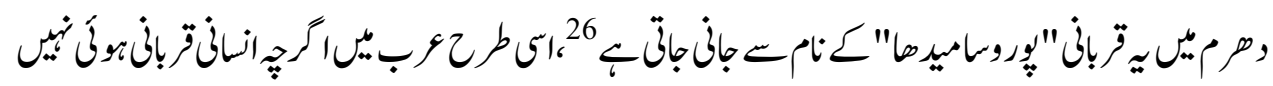

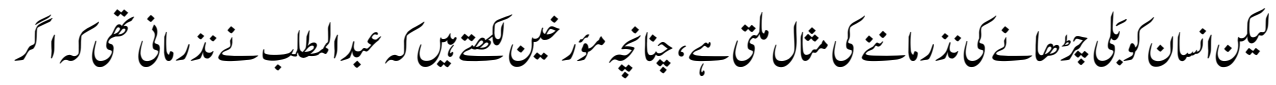

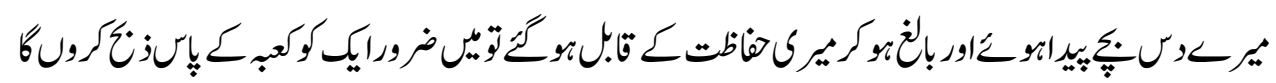

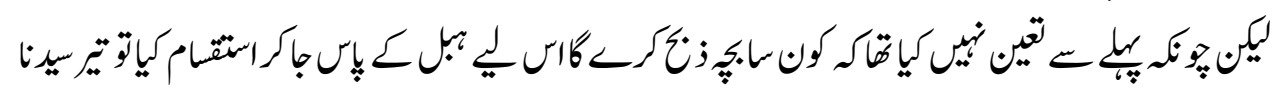

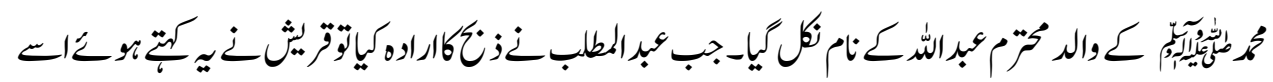

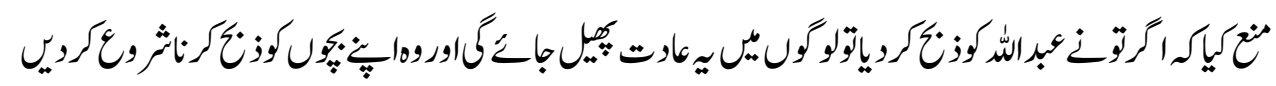

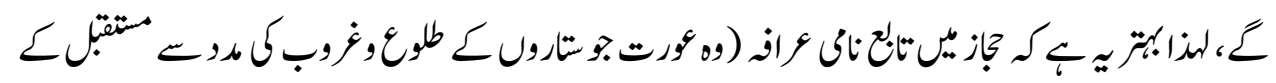

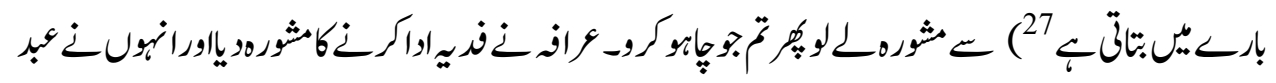

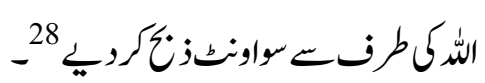

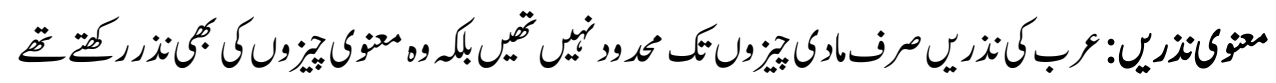

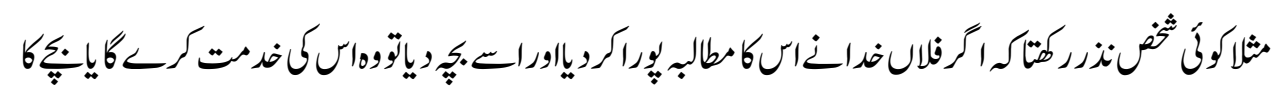

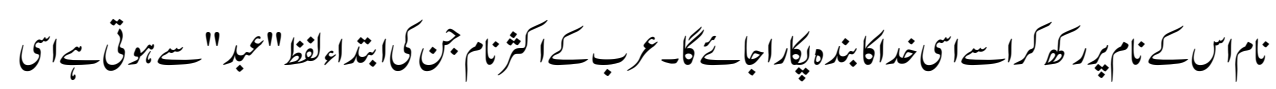

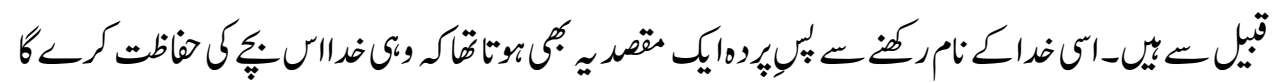

$$
\text { ج }
$$

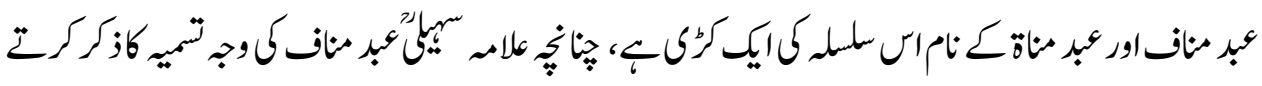

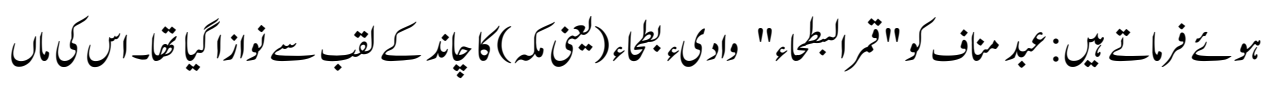

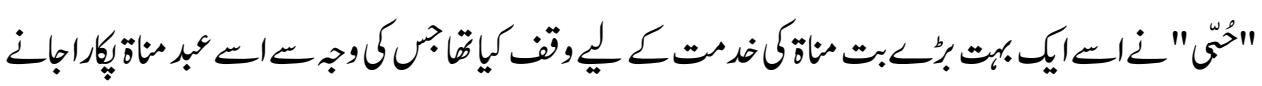

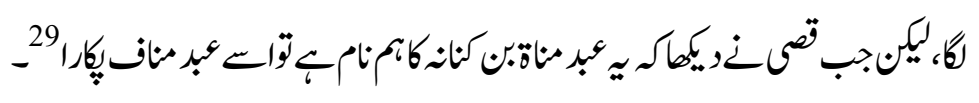




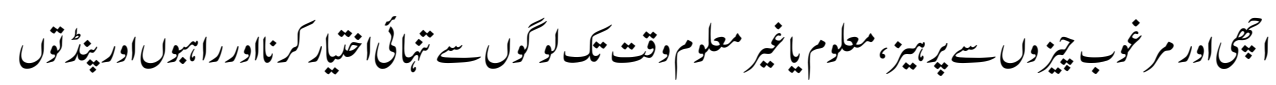

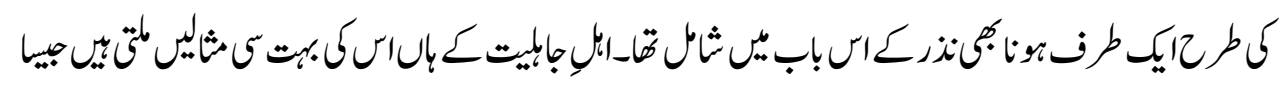

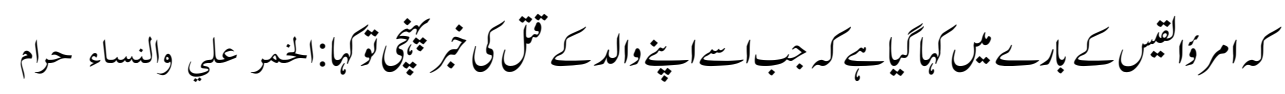

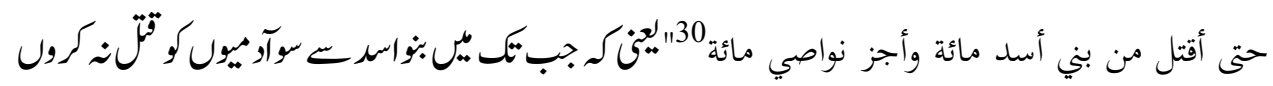

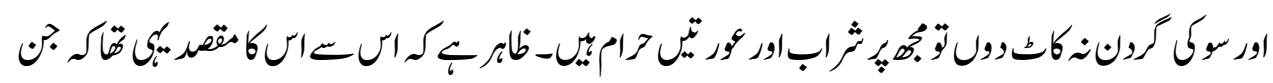

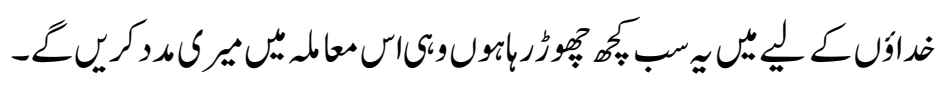

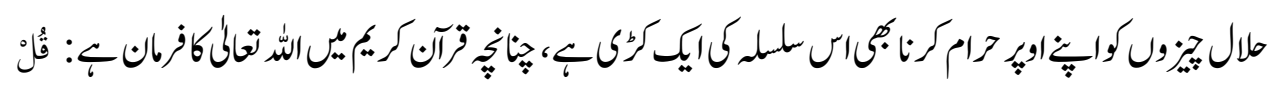

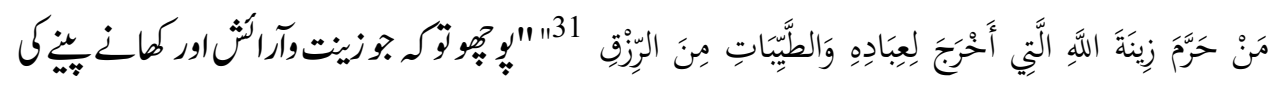

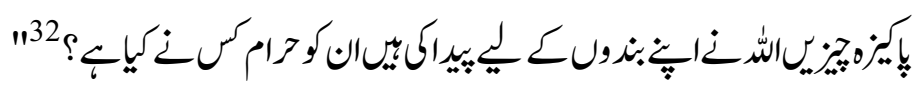

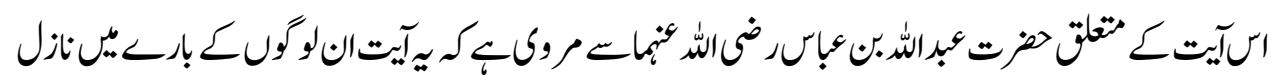

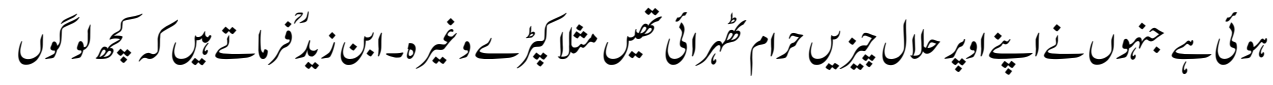

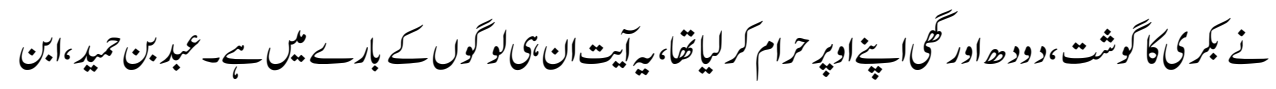

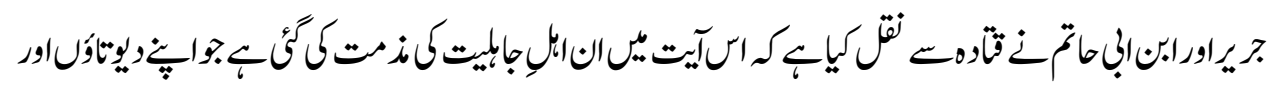

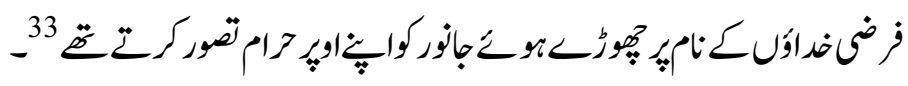

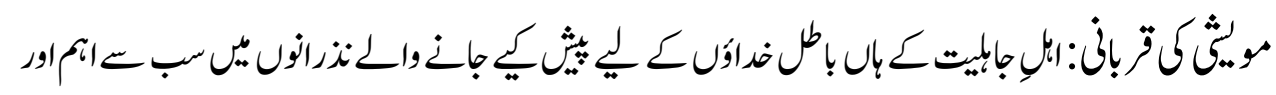

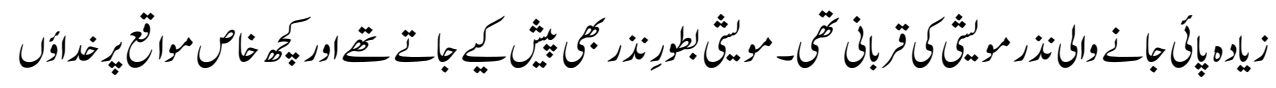

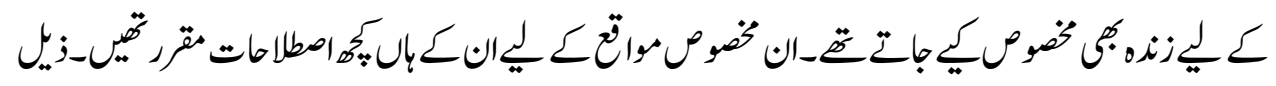

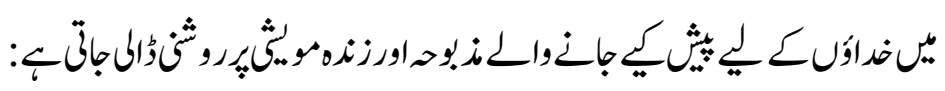

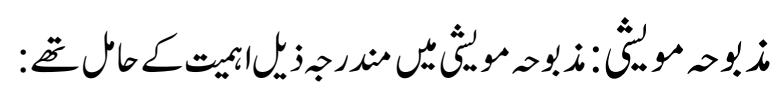

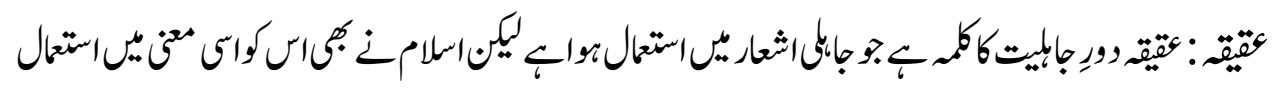

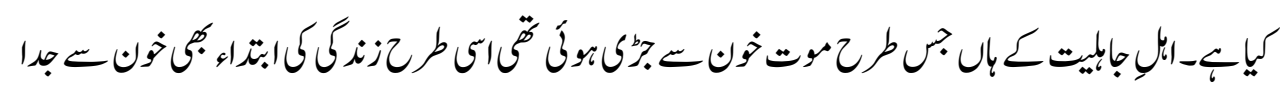

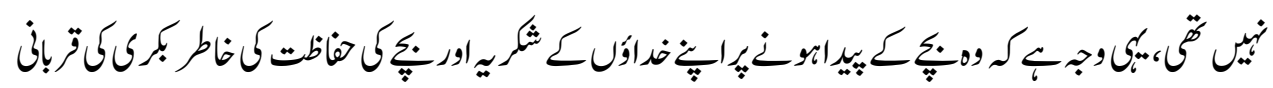

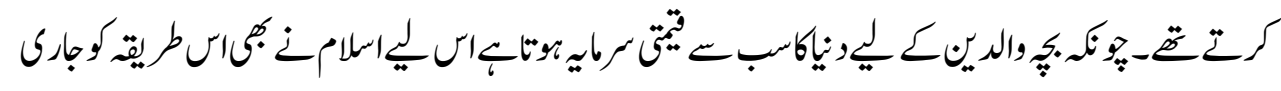




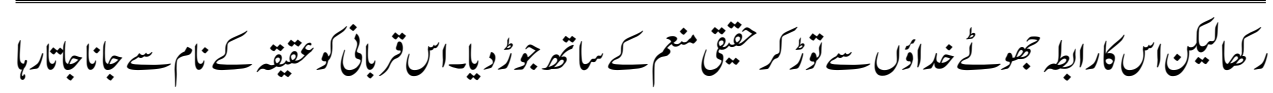

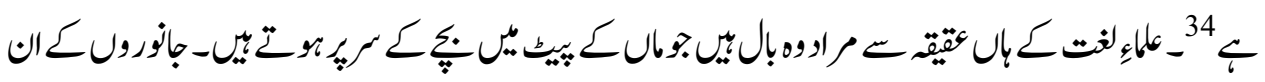

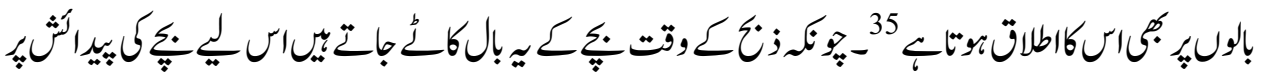

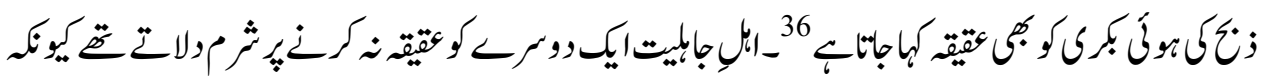

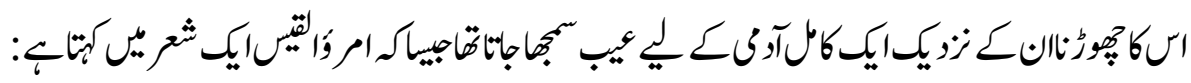

$$
\begin{aligned}
& \text { أيا هند لا تنكحي بوهة }
\end{aligned}
$$

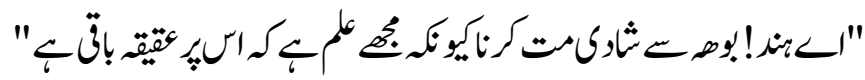

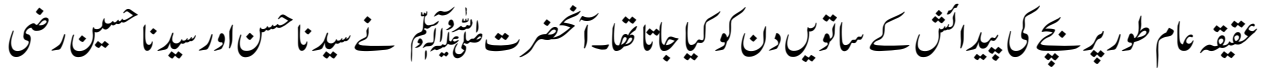

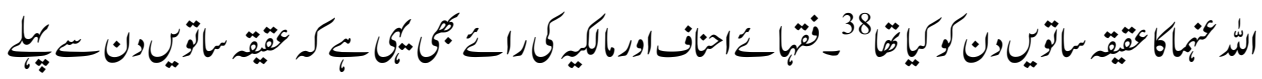
$-396=6$

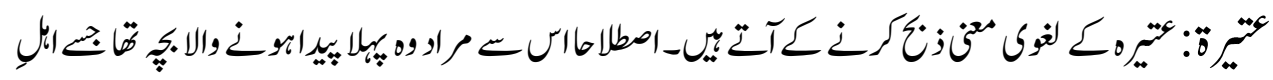

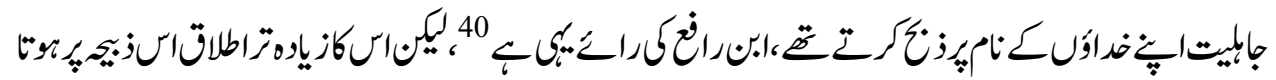

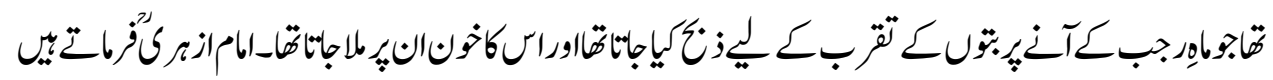

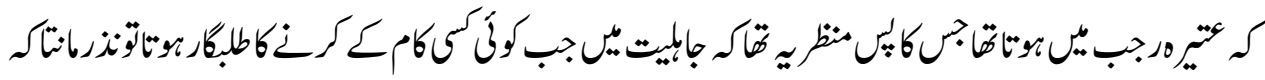

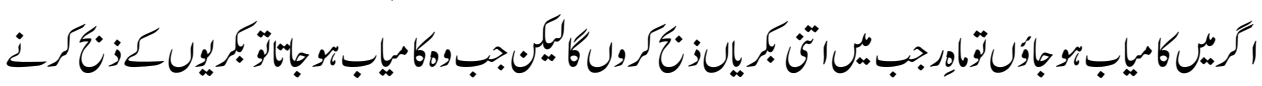

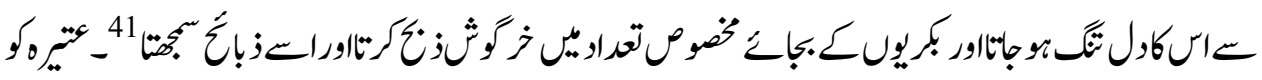

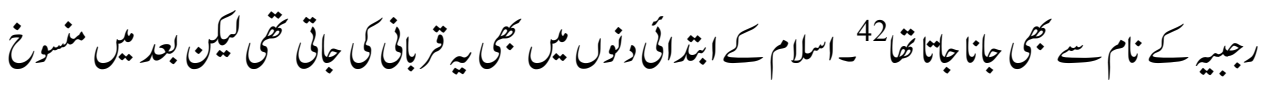

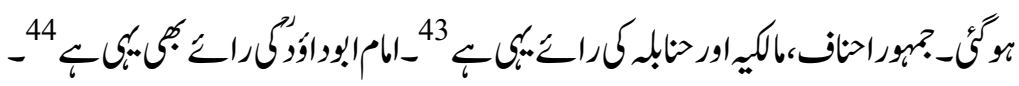

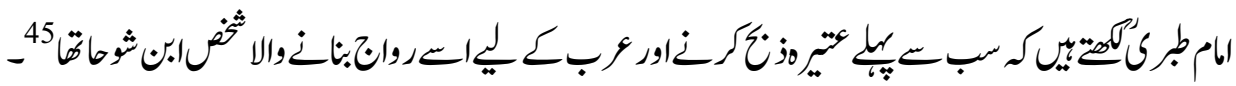

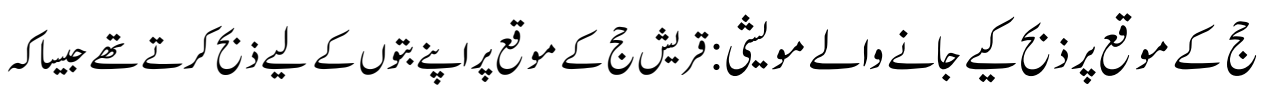

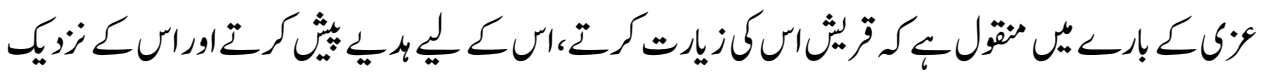

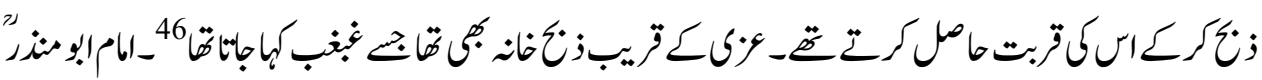

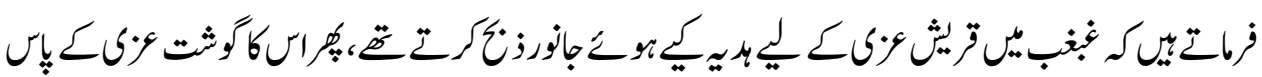




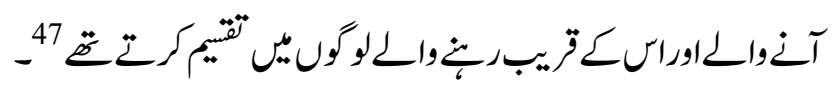

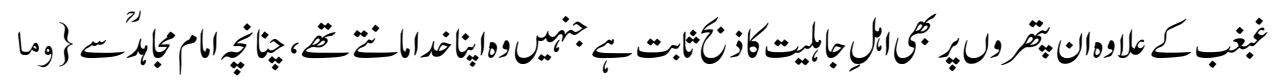

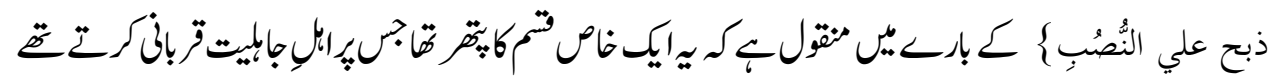

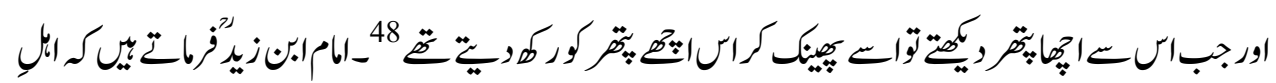

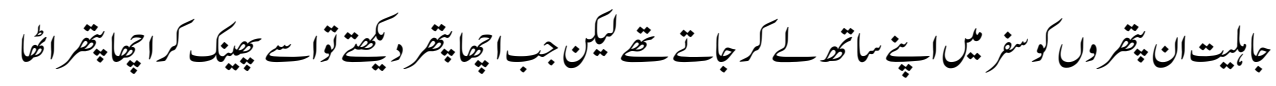

$$
\text { - ليّن }
$$

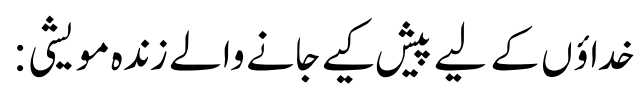

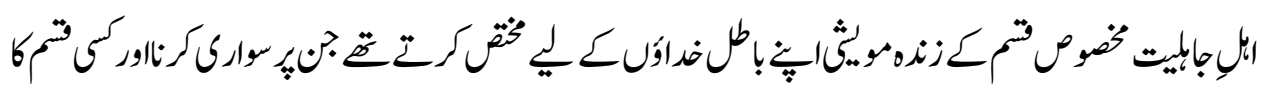

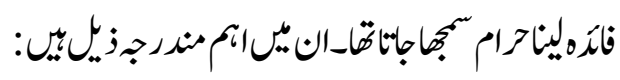

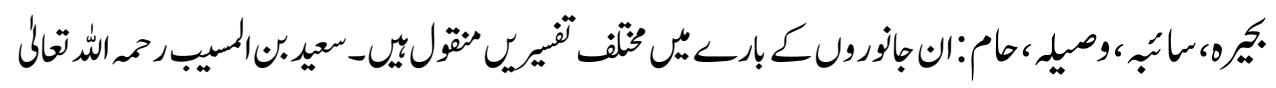

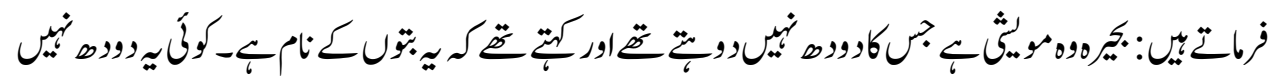

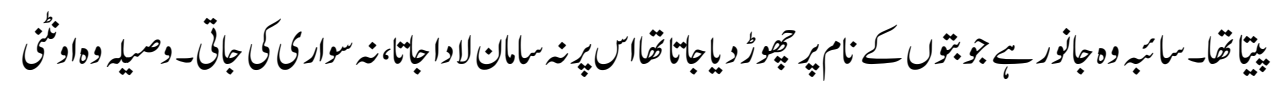

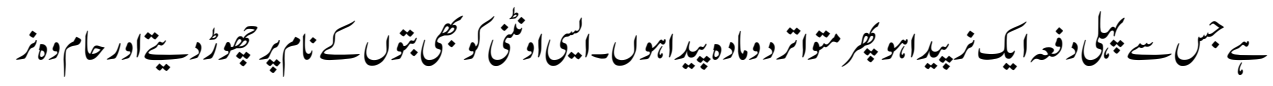

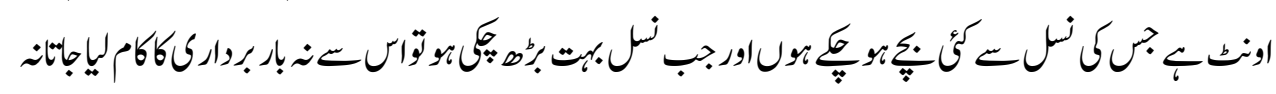

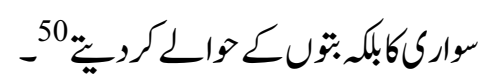

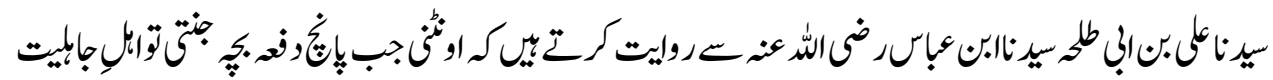

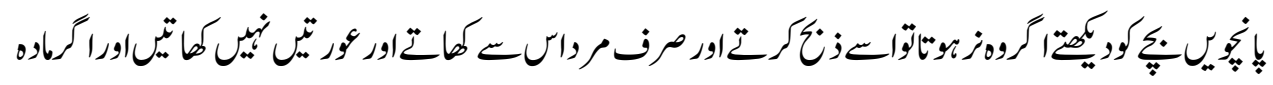

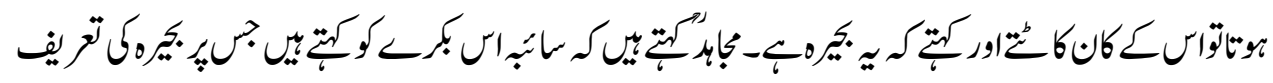

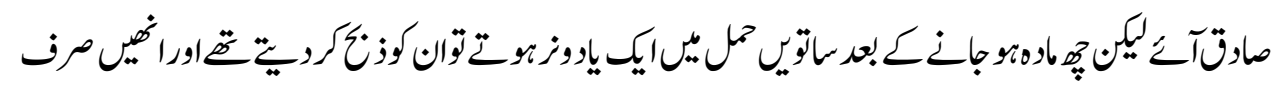

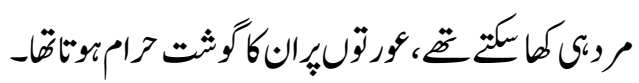

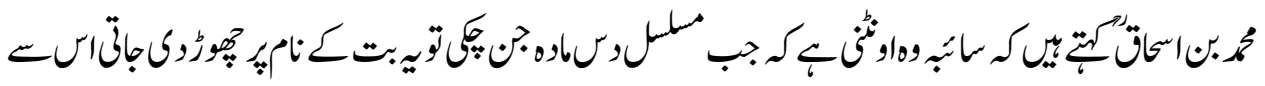

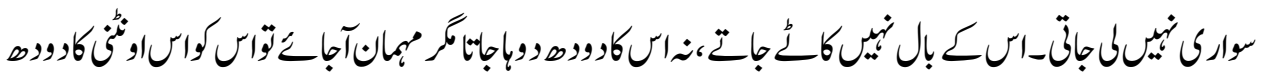

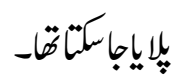




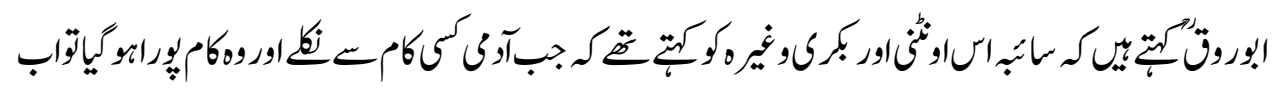

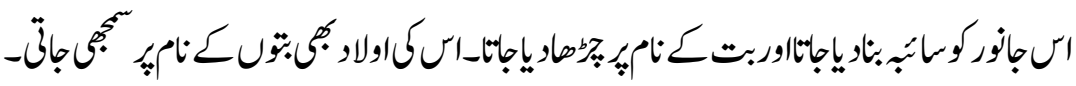

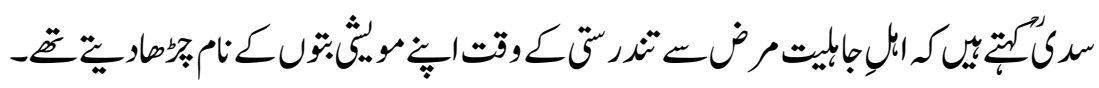

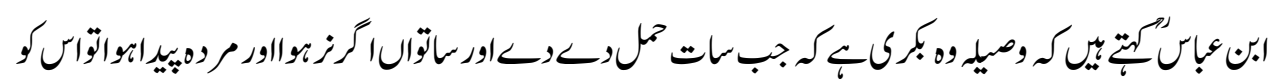

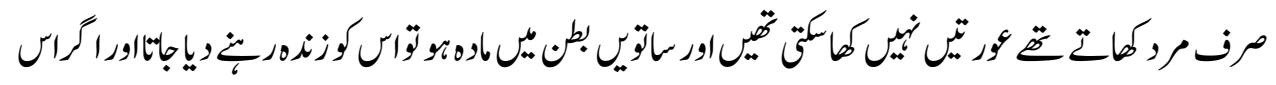

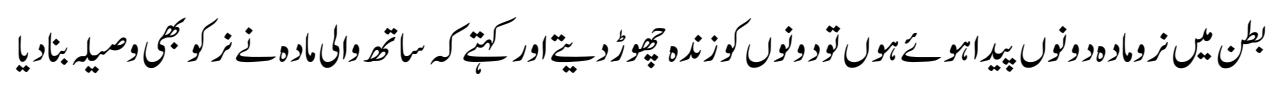

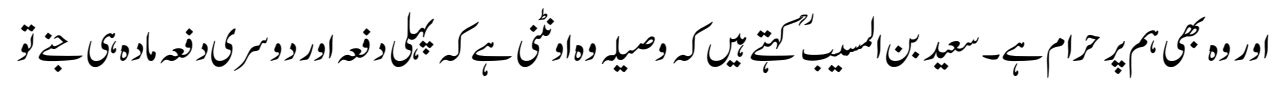

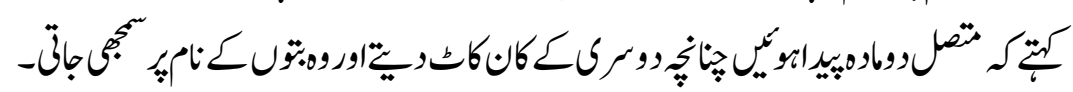

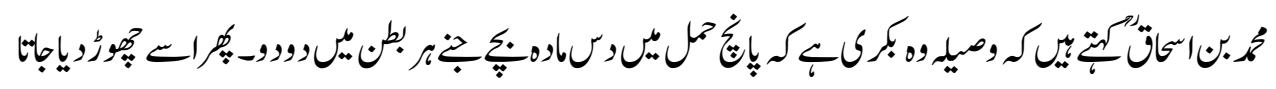

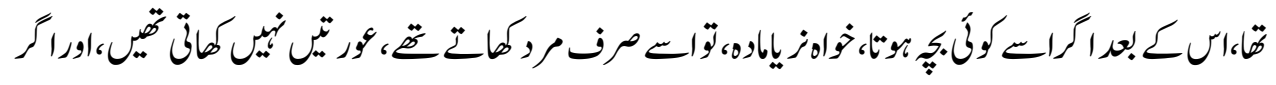

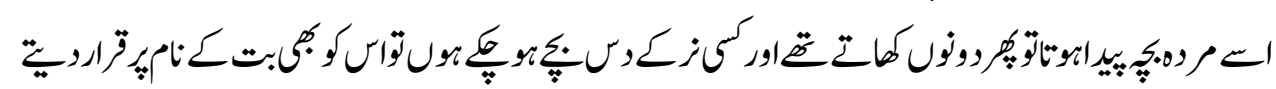

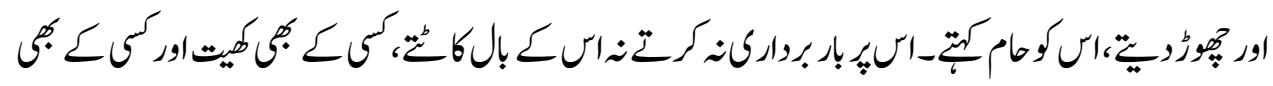

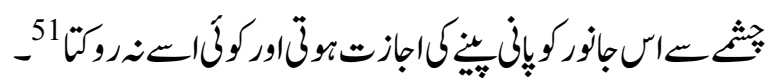

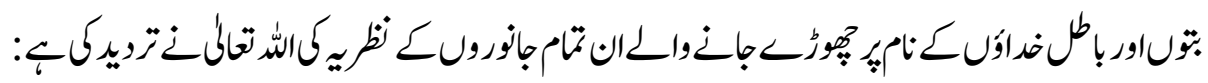

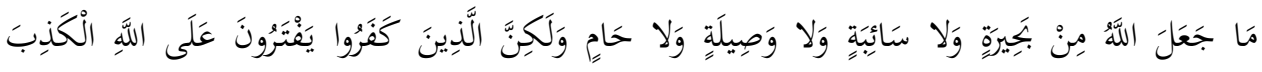

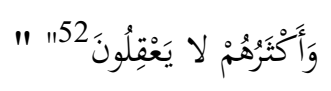

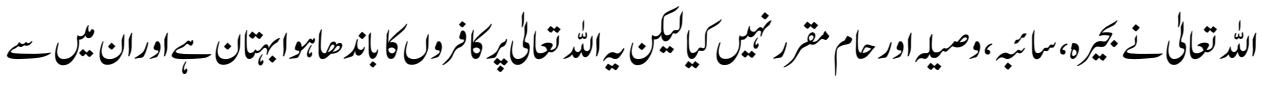

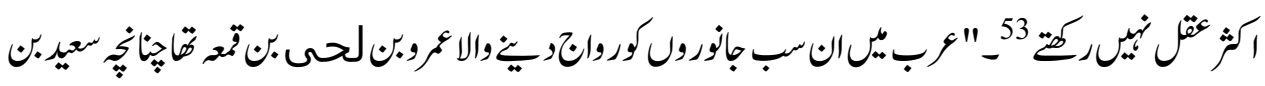

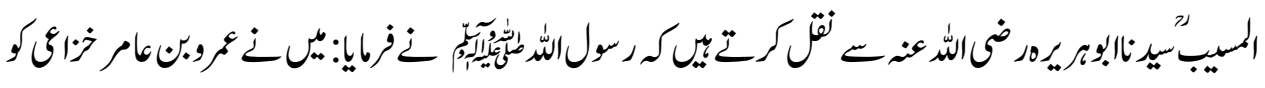

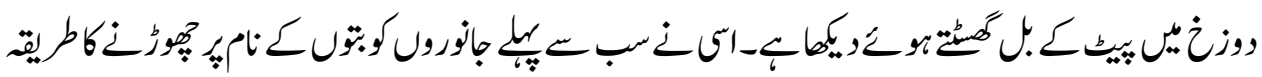

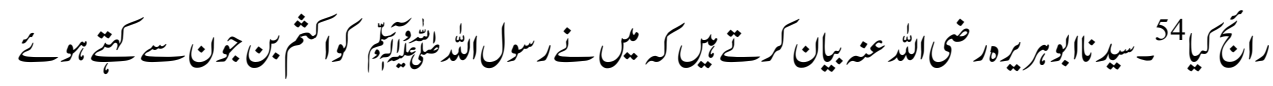

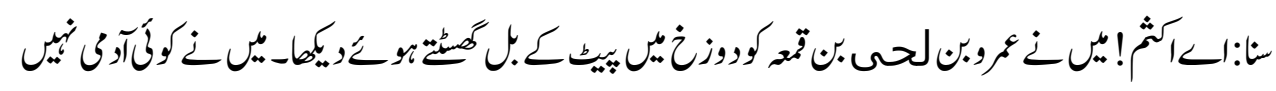

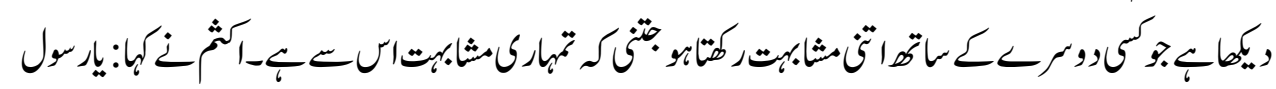

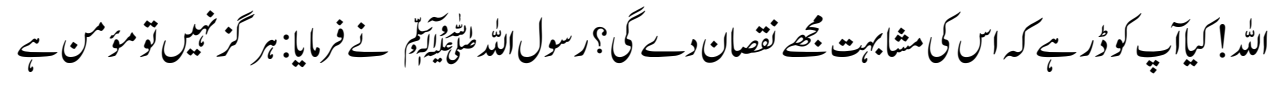




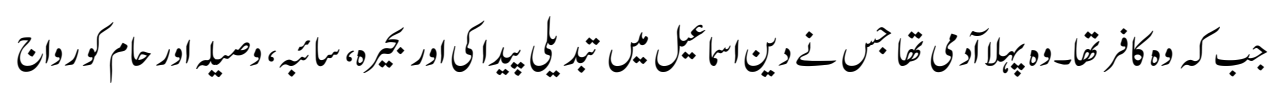

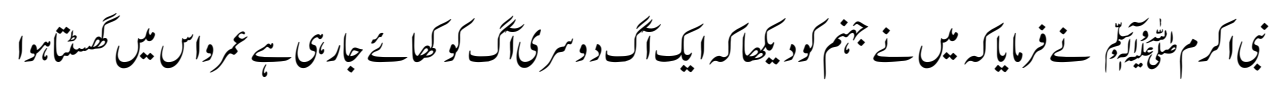

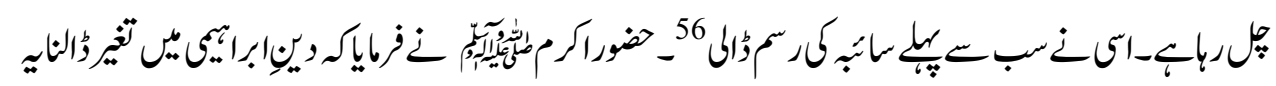

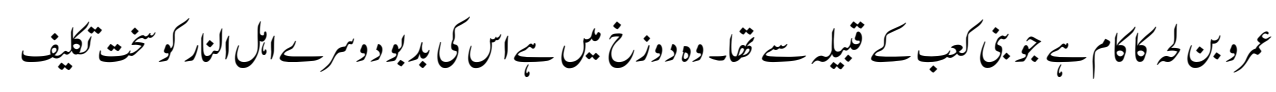

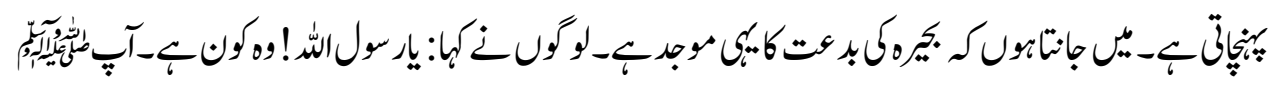

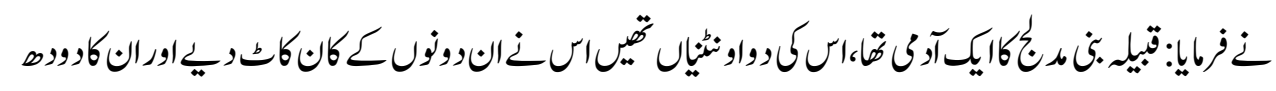

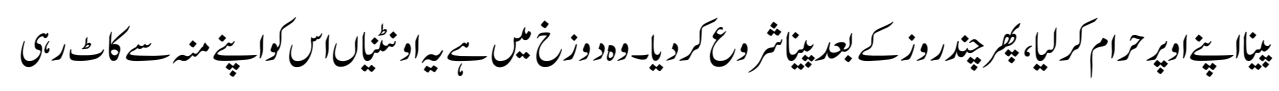

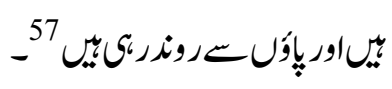
خلاص: - ماص:

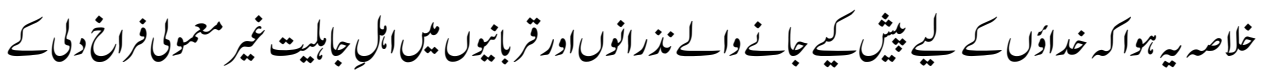

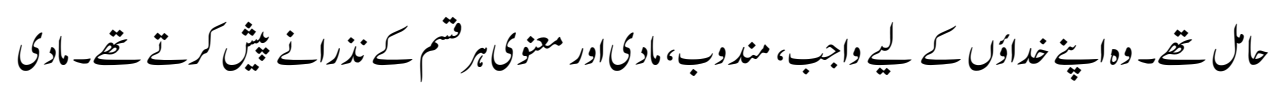

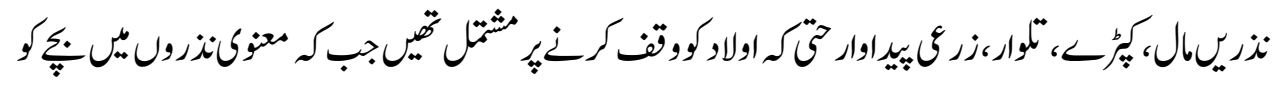

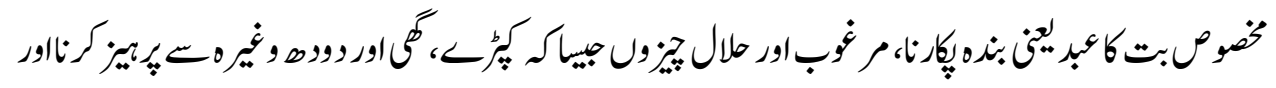

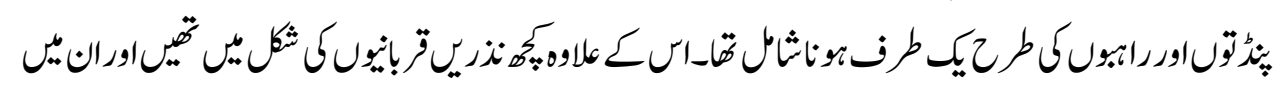

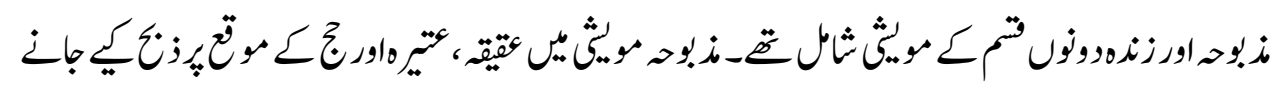

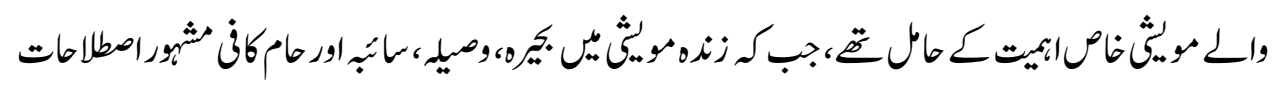

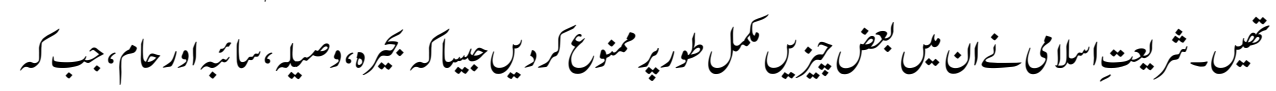

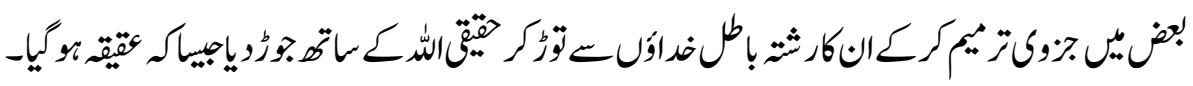

\section{(1)(9)(9)}

This work is licensed under a Creative Common Attribution-NonCommercial-ShareAlike 4.0 International (CC BY-NC-SA 4.0) 


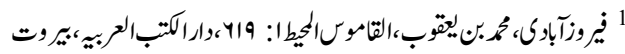

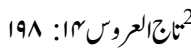

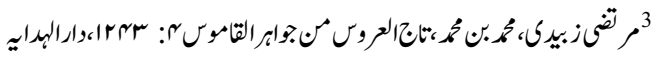

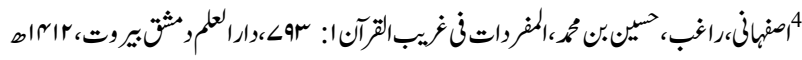

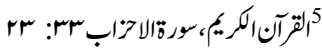

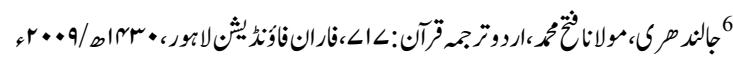

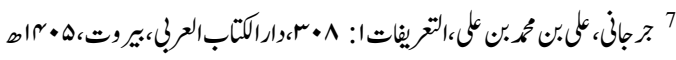

London, 1961, P.418, 421, 425, 429 ,Ancient Israel ${ }^{8}$ Roland De Vaux

${ }^{9}$ Encyclopedia Britannica, Volume: 25, P: 200

$$
10
$$

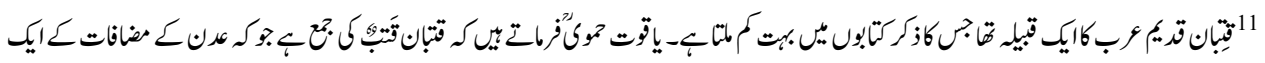

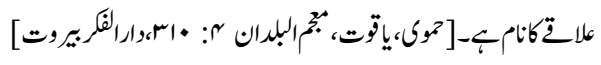

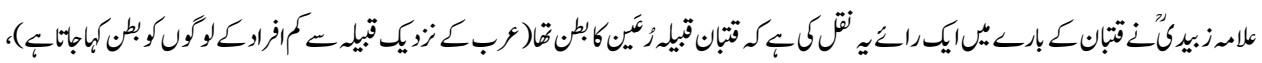

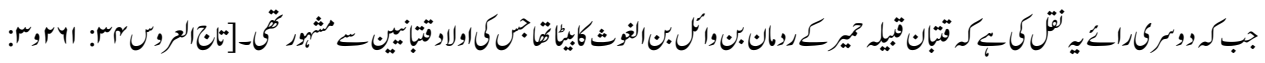

Texte, Ii, S. 41, Urkunden 1914 .Kataba , ${ }^{12}$ Nikolaus Rhodokanakis

$$
\begin{aligned}
& \text { 13 }
\end{aligned}
$$

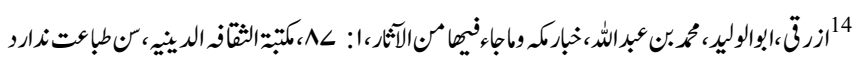

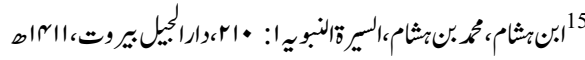

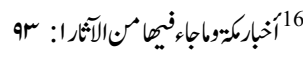

$$
\begin{aligned}
& \text { هN1: }
\end{aligned}
$$

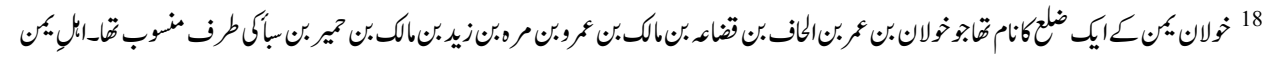

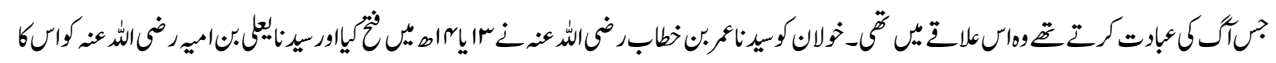

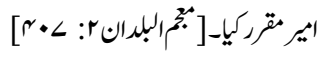

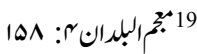

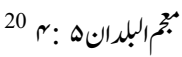

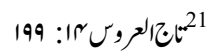

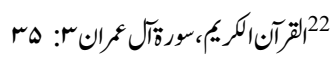$$
\text { 23 }
$$

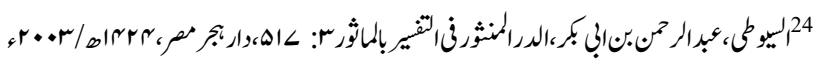

$r \cdot 1: 190$ 
${ }^{26}$ Klaus K. Klostermaier, A Concise Encyclopedia of Hinduism, P:157, Oneworld Oxford 2003

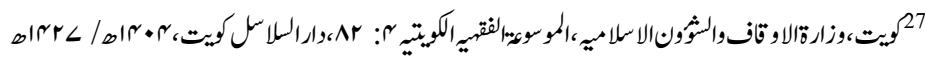

$$
\begin{aligned}
& \text { rA9 } \\
& \text { 29 } 29 \\
& \text { 130 }
\end{aligned}
$$

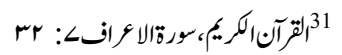

$$
\begin{aligned}
& \text { 32 }
\end{aligned}
$$

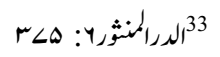

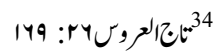

$$
\begin{aligned}
& \text { 149 } 145
\end{aligned}
$$

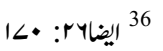

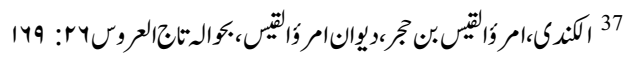

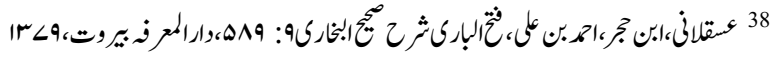

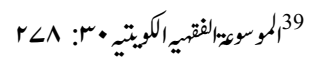

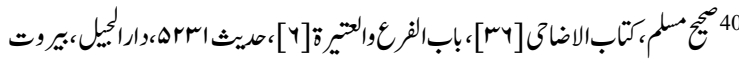

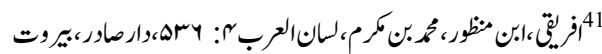

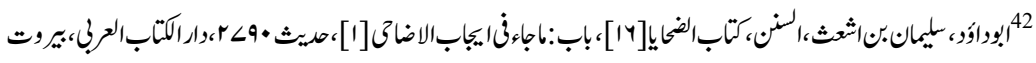

$$
\begin{aligned}
& r<1: r 9 \text { r r }
\end{aligned}
$$

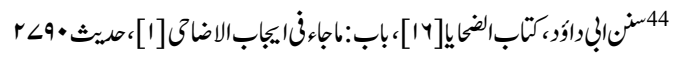

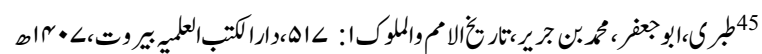

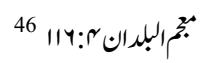

$$
\begin{aligned}
& \text { اليضا : } \\
& \text { L • • : ^ } \\
& \text { rr:rA< إيضا } 49
\end{aligned}
$$

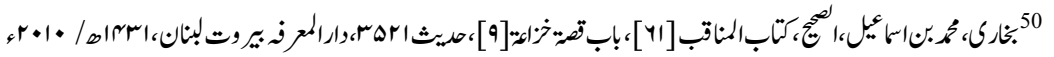

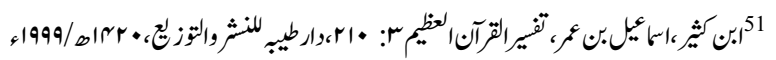

$$
\begin{aligned}
& \text { 1.r: : } \\
& \text { 1.r. : : 1. }
\end{aligned}
$$

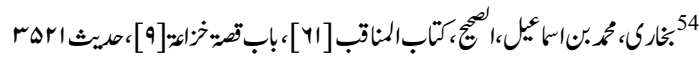

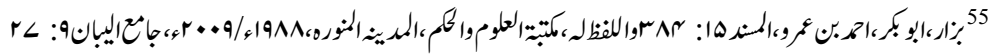

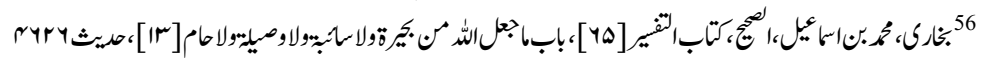

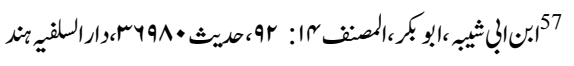

